\title{
Evaluation of Phytotoxicity of Bimetallic Ag/Au Nanoparticles Synthesized Using Geum urbanum L.
}

\author{
Marcin Szymanski ${ }^{1} \cdot$ Renata Dobrucka ${ }^{2}$
}

Received: 5 October 2020 / Accepted: 5 November 2020 / Published online: 16 November 2020

(c) The Author(s) 2020

\begin{abstract}
The growing production and wider application of metal nanoparticles gives rise to many concerns about their release to natural ecosystems. It is very important to be aware of the harmful impact of nanoparticles on living organisms, including plants. Therefore, it is of vital significance to explore the impact of metal nanoparticles on plants. This work assessed the phytotoxicity of bimetallic $\mathrm{Ag} / \mathrm{Au}$ nanoparticles and Geum urbanum L. extract. The obtained bimetallic $\mathrm{Ag} / \mathrm{Au}$ nanoparticles were characterized by UV-vis spectrophotometry (UV-vis), Transmission electron microscopy (TEM), Scanning electron microscopy (SEM), and Fourier transform infrared spectroscopy (FTIR). The microscopic studies enabled the determination of the size of the obtained nanoparticles, which was $50 \mathrm{~nm}$. The wide range of concentrations evaluated in the course of the study made it possible to observe changes in selected plants (seeds of Lepidium sativum, Linum flavum, Zea mays, Solanum lycopersicum var. Cerasiforme and Salvia hispanica-Chia) caused by a stress factor. The studies showed that the solution of $\mathrm{Ag} / \mathrm{Au}$ nanoparticles was most toxic to flax (IC50 $=9.83 \times 10^{-6} / 9.25 \times 10^{-6} \mathrm{mg} / \mathrm{ml}$ ), and least toxic to lupine (IC50 $\left.=1.23 \times 10^{-3} / 1.16 \times 10^{-3} \mathrm{mg} / \mathrm{ml}\right)$. Moreover, we studied the toxicity of Geum urbanum extract. The extracts diluted to $0.00875 \mathrm{mg} / \mathrm{ml}$ stimulated the growth of lupine, flax and garden cress; extracts diluted to $0.175 \mathrm{mg} / \mathrm{ml}$ stimulated the growth of Chia and tomatoes; and extracts diluted to $0.00875 \mathrm{mg} / \mathrm{ml}$ stimulated the growth of corn. G. urbanum extract was most toxic to lupine (IC50 $=0.374 \mathrm{mg} / \mathrm{ml})$, and least toxic to corn $(\mathrm{IC} 50=4.635 \mathrm{mg} / \mathrm{ml}$ ).
\end{abstract}

Keywords Bimetallic ag/au nanoparticles · Phytotoxicity · Geum urbanum L.

\section{Introduction}

Over several decades, nanotechnology has reinforced its position as a progressive and interdisciplinary field of science. Nanomaterials have various physico-chemical characteristics and can be applied in different innovative fields [1]. They have contributed to the commercial revolution, which has led to the production of hundreds of new products. The most interesting solutions are brought by combining metal nanoparticles [2,3]. Therefore, recently scientists have been

Renata Dobrucka

renata.dobrucka@ue.poznan.pl

1 Centre for Advanced Technologies, Adam Mickiewicz University in Poznań, ul. Uniwersytetu Poznańskiego 10, 61-614 Poznan, Poland

2 Department of Non-Food Products Quality and Packaging Development, Institute of Quality Science, Poznań University of Economics and Business, al. Niepodległości 10, 61-875 Poznan, Poland interested in bimetallic nanoparticles. Bimetallic nanoparticles have different physical and chemical properties due to the fact that they constitute a combination of two metals with different characteristics as well as exhibit additional properties typical of metals at the nanoscale. For this reason, bimetallic nanoparticles have become the basis for the search for and design of new materials (nanomaterials) that have unique sets of properties. This is why researchers working in engineering and academic fields of various kinds are becoming more interested in them [4-7]. One significant aspect of nanotechnology is related to the process of synthesizing nanoparticles. There are various methods for synthesizing metal nanoparticles, such as physical vapor deposition, chemical vapor deposition, sol-gel method, microwave-assisted synthesis, ultrasonication method, electrochemical synthesis, and chemical reduction of metallic ions.

Even though conventional chemical methods make it possible to easily control, to a certain extent, the shape of synthesized nanoparticles, they have two major disadvantages: the cost and the application of toxic chemicals [8]. Metallic 
nanoparticles have been produced using non-toxic, inexpensive and energy-efficient methods, which make use of plants, algae, fungi, bacteria and viruses. The use of phytochemicals in the synthesis of nanoparticles constitutes an important symbiosis between nanotechnology and green chemistry [9]. Green synthesis of metal nanoparticles has several advantages, such as better biocompatibility, convenient scale-up, quick [10], uncomplicated reaction procedures, and more. This is evidenced by the research in which synthesis cadmium telluride quantum dots [11] and zinc telluride quantum dots [12] was used the aqueous extract of the Ficus johannis plant.

Silver and gold nanoparticles are often used for medical purposes and in commercial products, including food packaging, labelling of fibrils and flagella in biofilms [13], antibacterial, and antiviral agents or personal care products. The growing production and use of metal nanoparticles gives rise to serious concerns about their migration to water, soil and air, and the resulting potential adverse impact on the environment and human health [14].

The world literature sometimes reports on the impact of nanoparticles on plant organisms. For years, plants have been used as bioindicators to assess a potential threat to the environment [15]. Nanoparticles taken up by plants are transported to different plant parts and inflict serious damage. Air is the second major source of metal nanoparticle contamination. Due to their small sizes, after reaching the environment, nanoparticles interact with air and enter into reactions (photolysis and oxidation) with other components. This triggers the release of toxic by-products, which are harmful to plants [16]. The world literature contains little information about the influence of bimetallic nanoparticles on plant growth. In response to this, it was created current work. Novelty in this work, it is the evaluation of acute phytotoxicity bimetallic $\mathrm{Ag} / \mathrm{Au}$ nanoparticles synthesized biologically using Geum urbanum L. wobec the seeds of Lepidium sativum, Linum flavum, Zea mays, Solanum lycopersicum var. Cerasiforme and Salvia hispanica-Chia.

\section{Materials and Methods}

\subsection{Materials}

The studies were carried out with the use of reagents purchased from Sigma - Aldrich (Poland) and demineralized water (J.T. Baker). The studies used the seeds of Lepidium sativum (manufacturer: BIO Garden ress - Certified ecological seeds), Linum flavum (Bio Planet), Zea mays, Solanum lycopersicum var. Cerasiforme (Vilmorin) and Salvia hispanica-Chia (GutBio), as well as Aerosil 200 (Evonik Resource Efficiency GmbH; Nr CAS 112945-52-5).

\subsection{Synthesis of Bimetallic Ag/Au Nanoparticles Synthesized Using Geum urbanum L.}

The synthesis of bimetallic $\mathrm{Ag} / \mathrm{Au}$ nanoparticles started with making the extract of G. urbanum L. by combining $10 \mathrm{~g}$ of powdered G. urbanum L. and $100 \mathrm{ml}$ of double distilled water. The prepared solution was heated and stirred vigorously for $55 \mathrm{~min}$ at $60^{\circ} \mathrm{C}$. Then, the obtained extract was filtered through Whatman's No. 1 filter paper, and used straight away. The next step consisted in the preparation of solution I $\left(5 \mathrm{mM} \mathrm{AgNO}_{3}\right.$ ) and solution II ( $\left.5 \mathrm{mM} \mathrm{HAuCl}_{4}\right)$. Then, two solutions were combined at a $1: 1$ ratio. The solution was stirred for 12,18 and $24 \mathrm{~h}$ at $65^{\circ} \mathrm{C}$, which was followed by absorbance readings.

\subsection{Characterization of Bimetallic Ag/Au Nanoparticles Synthesized Using Geum urbanum $\mathrm{L}$.}

The UV-vis absorption spectra of bimetallic Ag/Au nanoparticles were obtained using a spectrophotometer Cary E 500 in the range of $300-800 \mathrm{~nm}$. Fourier transform infrared spectroscopy (FTIR) (Perkin Elmer Spectrum 1000) was used to analyze the stretching and bending vibrations in the bimetallic Ag/Au nanoparticles. A Transmission Electron Microscope JEOL JEM 1200 EXII operating at $200 \mathrm{kV}$ was used to characterize the morphology of the bimetallic $\mathrm{Ag} /$ Au nanoparticles synthesized using G. urbanum L. A Scanning Electron Microscope Helios NanoLab 660 (FEI) was used to measure the size of nanoparticles. SEM imaging was performed in the immersion mode.

\subsection{Preparation of Dilutions of the Extract/Stock Solution}

The extract and the stock solution were diluted to obtain the following concentrations: G. urbanum extract (for lupine seeds: $0.000875 ; 0.00875 ; 0.0175 ; 0.1750 ; 0.4375 ; 0.875$; $1.750 ; 8.75 \mathrm{mg} / \mathrm{ml}$; for corn seeds: $0.000875 ; 0.00175$; $0.0175 ; 0.1750 ; 0.4375 ; 0.875 ; 1.750 ; 8.75 \mathrm{mg} / \mathrm{ml}$; for flax seeds: $0.000875 ; 0.00175 ; 0.00875 ; 0.08750 ; 0.175$; $0.4375 ; 1.750 ; 4.375 \mathrm{mg} / \mathrm{m}$; for Chia, tomato, garden cress seeds: $0.00875 ; 0.175 ; 0.4375 ; 1.750 ; 3.500 ; 4.375 ; 7.000$; $8.750 \mathrm{mg} / \mathrm{m}$ ); $\mathrm{Ag} / \mathrm{Au}$ nanoparticle solution (for lupine and corn seeds: $0.005 ; 0.010 ; 0.100 ; 1.00 ; 2.50 ; 10.0 ; 25.0$; $50.0 \%$; for flax seeds: $0.005 ; 0.010 ; 0.050 ; 0.500 ; 1.00 ; 1.50$; 2.00; $2.50 \%$; for Chia, tomato, garden cress seeds: 0.005 ; $0.010 ; 0.050 ; 0.100 ; 0.250 ; 0.500 ; 1.00 ; 2.50 \%)$. Then, $2.0 \mathrm{~g}$ of Aerosil 200 were weighed on a Petri dish and combined with $20 \mathrm{ml}$ of each dilution of the stock solution. The mixtures were stirred until they achieved a uniform consistency, 
and their surface was levelled. Demineralized water was added to the weighed Aerosil as a reference sample. Then, 20 seeds of lupine, corn, flax, Chia, tomato and garden cress, respectively, were placed onto the prepared substrate. They were put in an incubator (laboratory incubator 45L PRO) $\left(23.0^{\circ} \mathrm{C}\right.$ ) for $120 \mathrm{~h}$ (Chia, garden cress, flax) and $144 \mathrm{~h}$ (tomato, lupine, corn). After the incubation period, the dishes were taken out and plant growth was measured.

\subsection{Determination of IC50}

The measured values of plant growth or its inhibition, compared to the control sample, served as the basis for creating the chart showing the dependence of growth activity (A) $\{100 *$ (growth length of a respective seed-average length of the control sample)/average length of the control sample\} on concentration (C). IC50 (i.e. the concentration at which the growth of the test plant was inhibited by $50 \%$ ) was calculated on the basis of the equation $\mathrm{A}=\mathrm{a}^{*} \mathrm{C}+\mathrm{b}$. The linear range of $\mathrm{A}(\mathrm{C})$ dependence was determined from the whole range of the studied concentrations on the basis of a logarithmic dependence $\mathrm{A}=\mathrm{a}^{*} \ln (\mathrm{C})+\mathrm{b}$.

\section{Results and Discussion}

\subsection{UV-Vis Studies of Ag/Au Nanoparticles}

Figure 1 presents the UV-visible spectra of bimetallic Ag/ Au nanoparticles synthesized using G. urbanum L. after reaction at $60{ }^{\circ} \mathrm{C}$ for $12 \mathrm{~h}, 18 \mathrm{~h}$ and $24 \mathrm{~h}$. Absorbance increased over reaction time. As regards the reaction media, their absorption spectra showed absorbance at $550 \mathrm{~nm}$, confirming the presence of $\mathrm{Ag} / \mathrm{Au}$ bimetallic nanoparticles. It is known that nanoparticles prepared from extracts undergo three phases: activation phase, growth phase, and termination phase. In the activation phase, plant extract constituents with reduction capabilities in the form of phytochemicals (with $-\mathrm{OH}$ groups), reduce the metal ion from their salt precursors to a zero-valent state, which is followed by the nucleation of the metal atom. In the course of this process of biological reduction, the separated atoms of metal start to associate together. As a result, the growth phase intensifies the thermodynamic permanence of the nanoparticles and causes the accumulation of the synthesized nanoparticles, leading to alteration of their morphologies $[17,18]$. In this study, the reduction of metal salts caused by the biocomponents of G. urbanum L. extract made the solution gradually change its color.

\subsection{Fourier Transform Infrared Spectroscopy (FTIR) Studies of Ag/Au Nanoparticles}

The FT-IR measurement, as presented in Fig. 2, was carried out at room temperature, in the wave number range of 380 to $4000 \mathrm{~cm}^{-1}$, using the $\mathrm{KBr}$ method. The strong peaks appeared at $3324 \mathrm{~cm}^{-1}, 2127 \mathrm{~cm}^{-1}, 1635 \mathrm{~cm}^{-1}, 408 \mathrm{~cm}^{-1}$ and $396 \mathrm{~cm}^{-1}$. The strong absorption peak at $3324 \mathrm{~cm}^{-1}$ is associated with $-\mathrm{OH}$ stretching and the aliphatic methylene group -C-H stretching. The peak at $2127 \mathrm{~cm}^{-1}$ may be associated with the alkynes group. The most intense band at $1635 \mathrm{~cm}^{-1}$ represents $\mathrm{C}=\mathrm{O}$ vibrations typical of the structure of phenolic acids contained in G. urbanum L. The absorption bands at $408 \mathrm{~cm}^{-1}$ and $396 \mathrm{~cm}^{-1}$ indicated the creation of metal-biomolecules found in the extract. The comparison of the presence of the $\mathrm{OH}$ group and the $\mathrm{C}-\mathrm{O}$ group of acid in the extracts confirms their role in the process of reducing salt into the respective nanoparticles.
Fig. 1 UV-visible spectra of bimetallic $\mathrm{Ag} / \mathrm{Au}$ nanoparticles synthesized using G.urbanum L

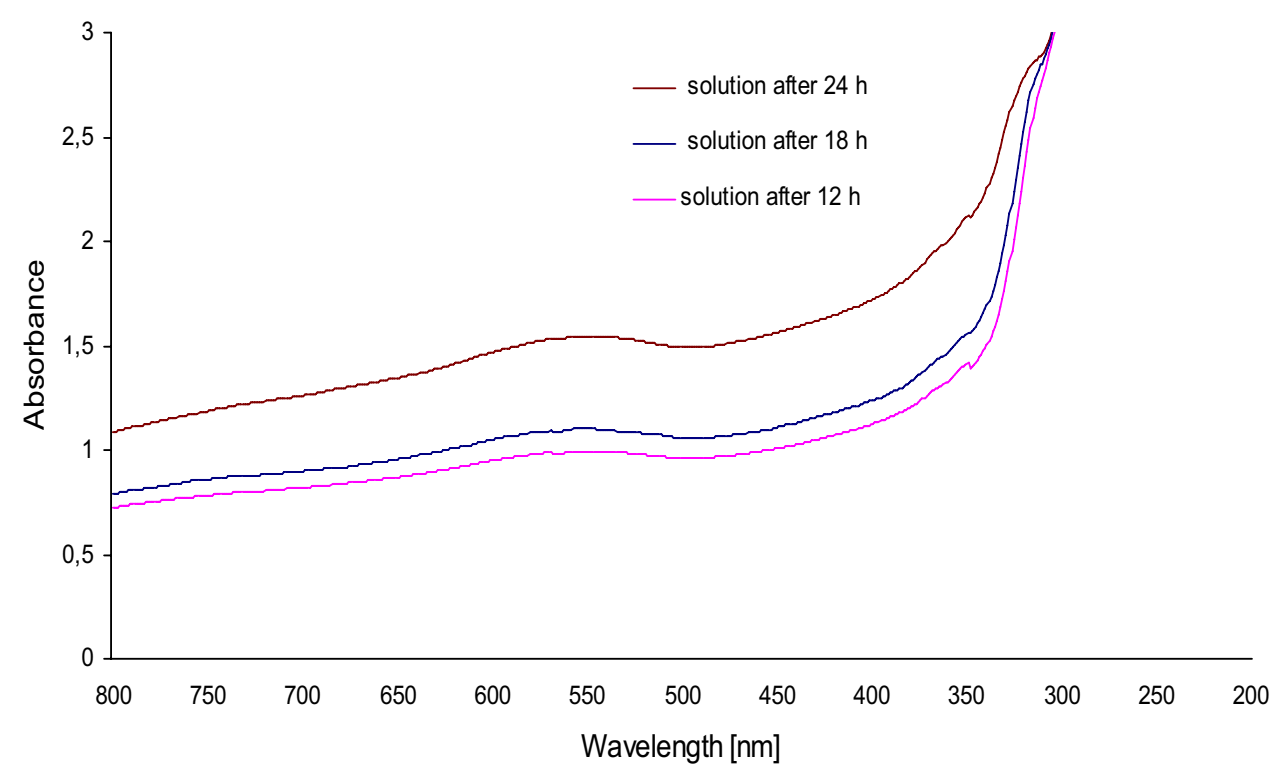




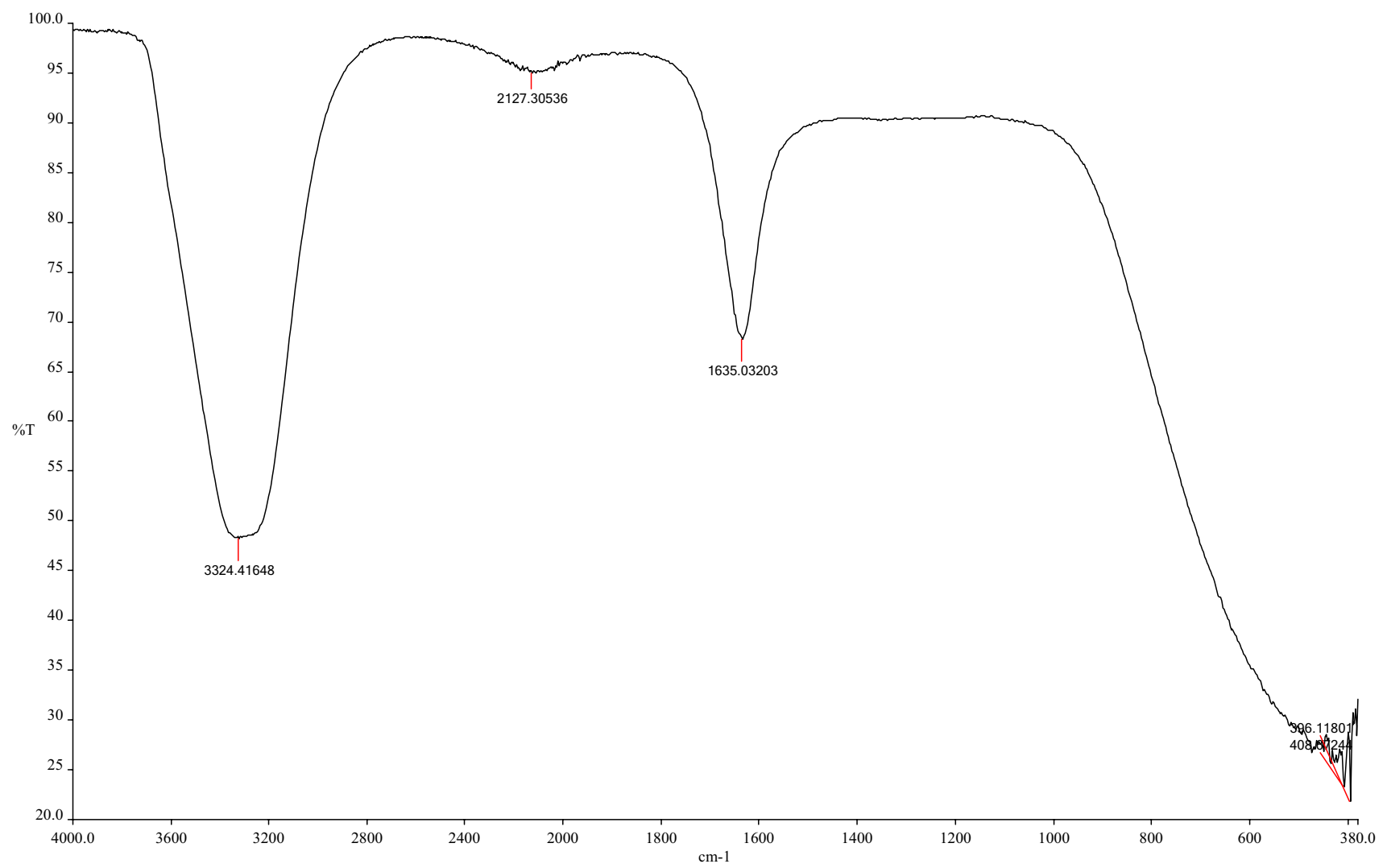

Fig. 2 FTIR spectra of the bimetallic Ag/Au nanoparticles synthesized using G. urbanum L

Fourier transform infrared spectroscopy (FTIR) studies confirmed the presence of bioactive compounds in $G$. urbanum $\mathrm{L}$. which act as reducing and capping agents for bimetallic $\mathrm{Ag} / \mathrm{Au}$ nanoparticles. According to the literature $[19,20]$ G. urbanum L. contains phenolic compounds (gallic, caffeic, chlorogenic acids), vicianose sugar, carotenoids, flavonoids, tannins (10.5\%), volatile oil, and sesquiterpene lactone (cnicin). The studies carried out by Kuczerenko et al. [21] made it possible to identify in G. urbanum certain compounds belonging to the group of tannins, such as (+)-catechin, (-)-epicatechin, (-)-epigallocatechin, (-)-epicatechin gallate, (-)-epigallocatechin gallate, ellagic acid, and eugenol, a component of essential oil that is also a phenol.

The literature $[22,23]$ has reported that the majority of phenolic acids found in plants are in the bonded form, as esters or glycosides, as components of lignins and hydrolyzing tannins. Their structures are represented mainly by a phenolic ring and an organic carboxylic acid function, including also compounds that have one $\mathrm{C} 6$ aromatic ring of hydroxybenzoic acids. The antioxidant properties of phenolic compounds have been associated with various mechanisms. The antioxidant activity of these compounds can be evaluated using many different techniques. The alkylperoxyl radical (ROO) and $\mathrm{O}_{2}{ }^{-}$radical are most often considered the biologically relevant active free radicals which can be effectively scavenged to delay oxidative destruction [24]. When compounds have one hydroxyl group, their antioxidant activity is additionally increased by one or two methoxy groups present in the ring. The antioxidant properties of phenolic acids become more stable when the ortho-position becomes occupied by a group with electron donors, for example an alkyl group or a methoxy group. Figure 3 shows the chemical structure of bioactive compounds present in G. urbanum L.: (A) gallic acids, (B) caffeic acid, (C) chlorogenic acids and (D) ellagic acid.

\subsection{SEM and TEM Analysis of Ag/Au Nanoparticles}

The structure of bimetallic Ag/Au nanoparticles synthesized using $G$. urbanum L. extract was determined by means of Transmission Electron Microscopy, as it allows magnification that is much greater than in the case of conventional optical microscopes, which enables more detailed observation of the specimen. TEM involves a beam of electrons that passes through, and interacts with, an extremely thin specimen. When accelerated to a high extent (up to several hundreds of $\mathrm{keV}$ ) and focused on a given material, electrons can scatter or backscatter, elastically or inelastically, 
Fig. 3 The chemical structure of bioactive compounds present in G. urbanum L. a gallic acids, b caffeic acid, c chlorogenic acids, and $\mathbf{d}$ ellagic acid<smiles>O=C(O)c1cc(O)c(O)c(O)c1</smiles>

(A)<smiles></smiles>

(C)<smiles>O=C(O)/C=C/C1C=C(O)C(O)=CC1</smiles>

(B)<smiles>O=C(/C=C/c1cccc(O)c1O)O[C@@H]1C[C@H](C(=O)O)[C@H](O)[C@H](O)[C@H]1O</smiles>

as well as interact in many ways and emit various signals, e.g. X-rays, Auger electrons or light [25]. The Transmission electron microscopy images used in the work indicated the presence of spherical, triangular and hexagonal shapes characteristic of gold and silver nanoparticles. Scanning Electron Microscopy confirmed the presence of bimetallic $\mathrm{Ag} / \mathrm{Au}$ nanoparticles of about $50 \mathrm{~nm}$. Figure 4 shows the SEM and TEM images of bimetallic $\mathrm{Ag} / \mathrm{Au}$ nanoparticles synthesized using G. urbanum L. extract at the following magnifications: (a) $\times 50,000$, (b) $\times 30,000$, (c) $\times 5000,(d) \times 1500$; and with the scale bar of (e) $50 \mathrm{~nm}$, and (f) $100 \mathrm{~nm}$.

\subsection{Determination of the Inhibitory Concentration $50 \%$ (IC50)}

Phytotoxicity plays a significant role in understanding the potential impact of manufactured nanomaterials on the environment [26]. According to the world literature, most nanoparticles are toxic at some concentrations. They affect the productivity of crops by changing their morphoanatomical, physiological, biochemical and genetic constitutions. Some studies have shown the phytotoxic activity of metal nanoparticles resulting from the production of reactive oxygen species (ROS), which leads to oxidative stress, lipid peroxidation, as well as protein and DNA damage in plants.

According to the literature, small nanoparticles $(<50 \mathrm{~nm})$ are able to easily penetrate and pass into the lymphatic system. Subsequently, they can reach and harm the vital organs and body tissues [27]. Nanoparticles of various sizes are taken up by plants, translocated to shoots and accumulated in various aerial parts, which increases the possibility that they will be cycling in the ecosystem through various trophic levels. Accumulated nanoparticles start to degrade the quality of crops. They lower seed germination rate, decrease fresh and dry biomass as well as the length of roots and shoots, alter photosynthesis, enhance chromatin condensation, cause a greater DNA damage, reduce transpiration rate, increase lipid peroxidation, cause the up- and down-regulation of various stress-related genes, and finally apoptosis. Plants have certain inherent defense strategies to overcome the toxic impact of stress conditions, including nanoparticles. To combat stress, plants can activate many different enzymatic 


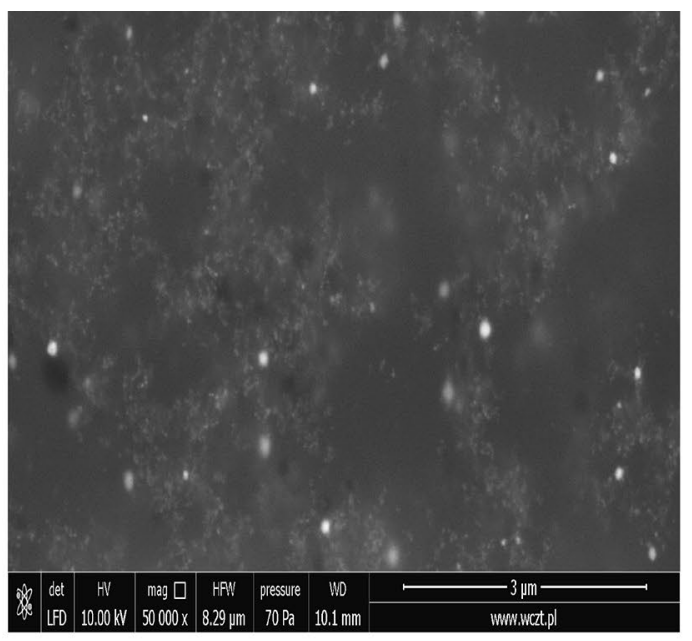

(A)

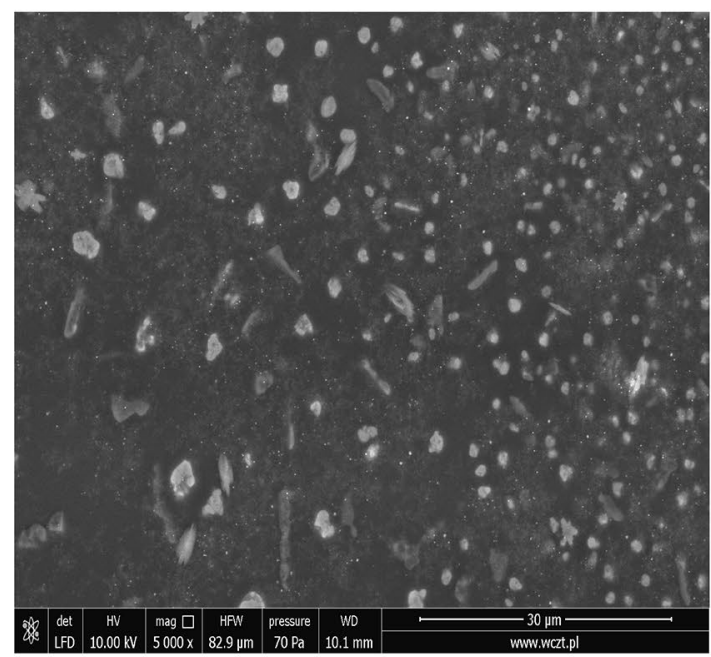

(C)

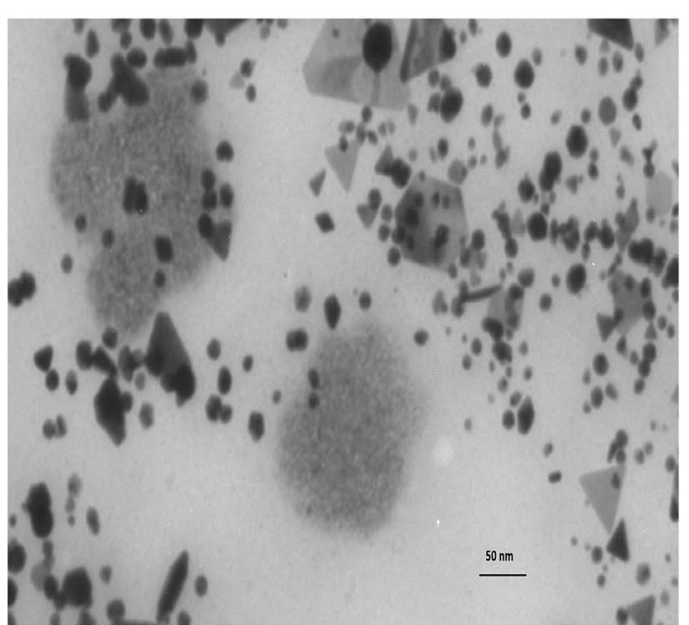

(E)

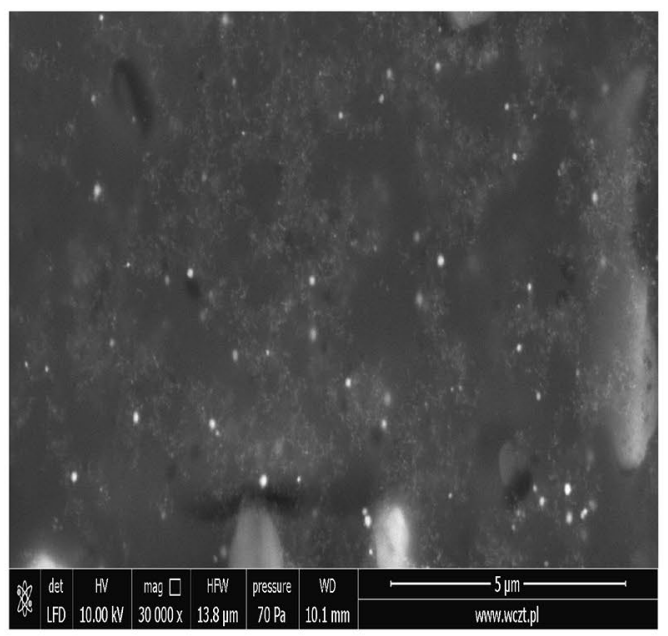

(B)

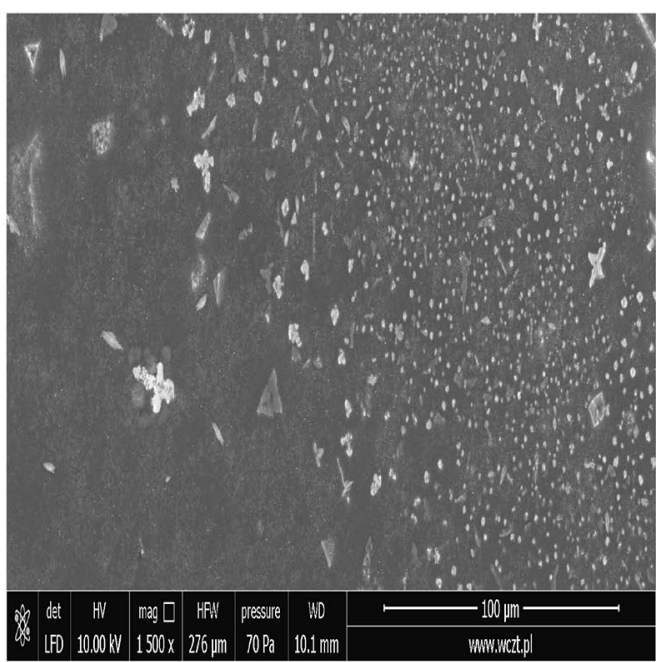

(D)

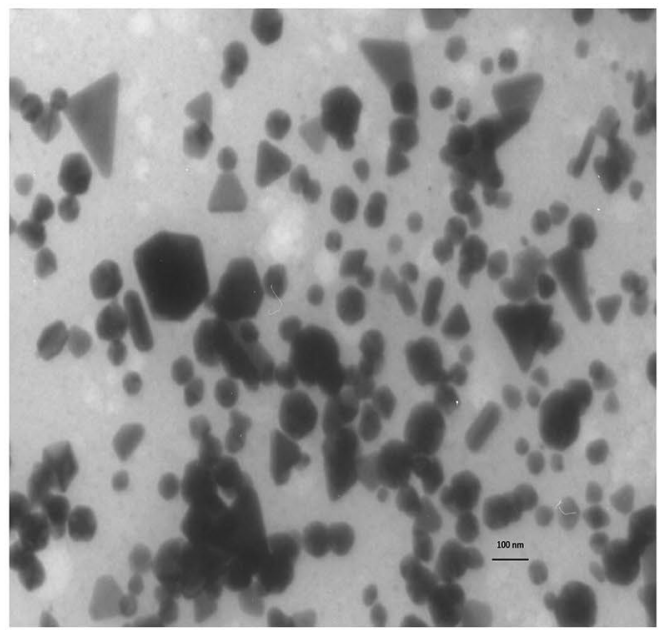

(F)

Fig. 4 SEM and TEM images of bimetallic Ag/Au nanoparticles synthesized using of using G. urbanum L. extract at magnification $\mathbf{a} \times 50,000$, $\mathbf{b} \times 30,000, \mathbf{c} \times 5000, \mathbf{d} \times 1500$ and with the scale bar e $50 \mathrm{~nm}, \mathbf{f} 100 \mathrm{~nm}$ 
Table 1 The identified IC50 parameters, curve equations and correlation parameters

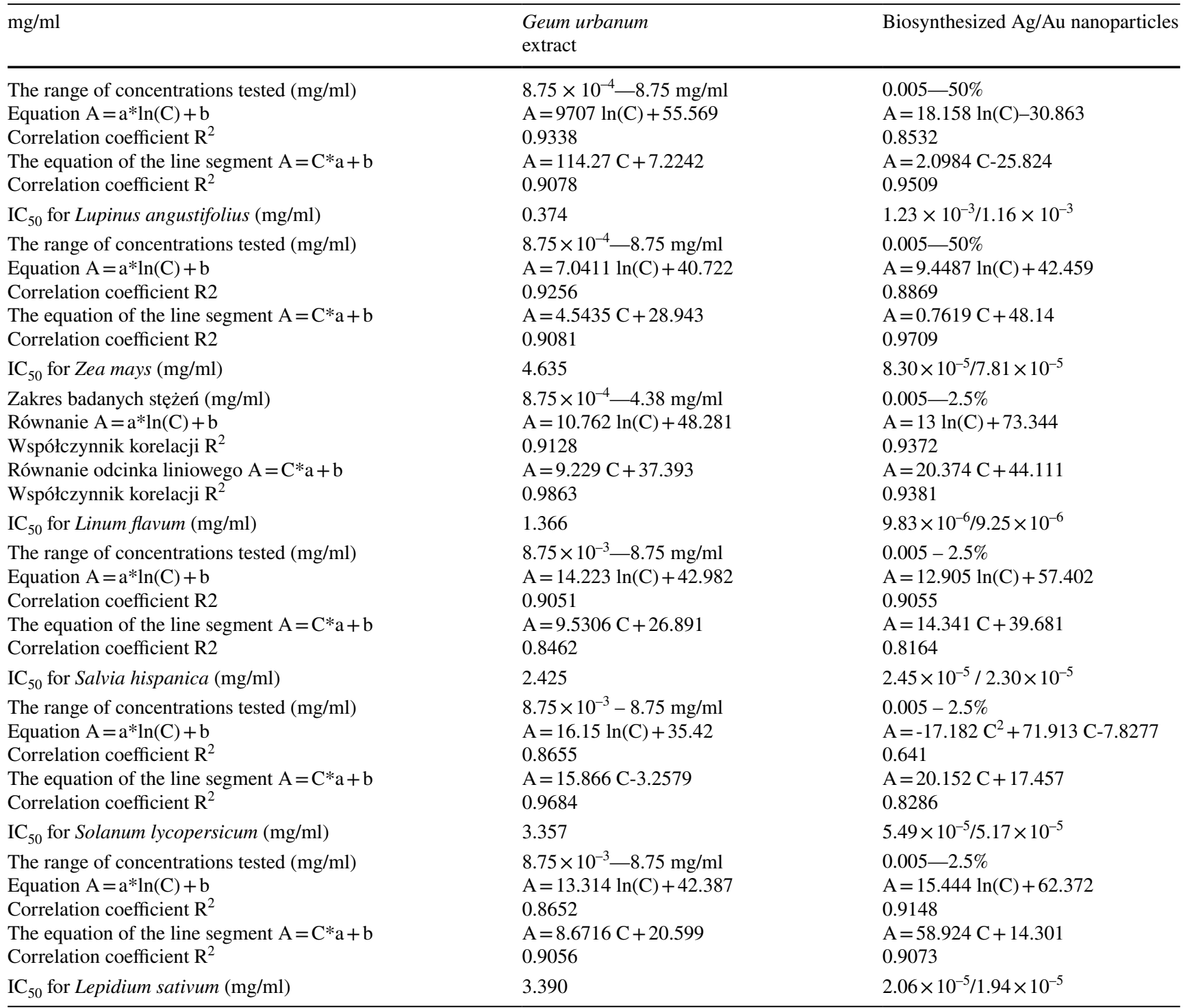

and non-enzymatic defense systems. However, beyond the limit of stress factors, the internal detoxification system does not manage to combat toxicity, which ultimately results in plant cell apoptosis [16].

This work assessed the phytotoxicity of $50 \mathrm{~nm}$ bimetallic Ag/Au nanoparticles, and G. urbanum L. extract. Seed germination and root elongation is a rapid and widely used acute phytotoxicity test with several advantages: sensitivity, simplicity, low cost and suitability for unstable chemicals or samples. The seeds of Lepidium sativum, Linum flavum, Zea mays, Solanum lycopersicum var. Cerasiforme and Salvia hispanica-Chia were used in this work due to the fact that several physicochemical variations among plant speciessuch as difference in hydraulic conductivity or pore size of the cell wall-might influence the transport and accumulation of nanoparticles. Moreover, the uptake and translocation of metal nanoparticles depend on their shape, size and composition [28]. The wide range of concentrations of G. extract and $\mathrm{Ag} / \mathrm{Au}$ nanoparticle solution made it possible to observe changes undergone by the selected plants under the influence of a stress factor. In almost all cases, both for the extract and the solution, there were observed logarithmic dependencies of growth activity on concentration $\left(\mathrm{R}^{2}\right.$ was from 0.8532 to 0.9372 ). One exception was the study of the phytotoxicity of $\mathrm{Ag} / \mathrm{Au}$ nanoparticles to a tomato; in that case, a polynomial relationship was observed $\left(\mathrm{R}^{2}=0.641\right)$. The conducted studies have shown that $G$. urbanum $\mathrm{L}$ extract was most toxic to lupine $\left(\mathrm{IC}_{50}=0.374 \mathrm{mg} / \mathrm{ml}\right)$, and least toxic to corn $\left(\mathrm{IC}_{50}=4.635 \mathrm{mg} / \mathrm{ml}\right)$. The solution of $\mathrm{Ag} / \mathrm{Au}$ nanoparticles was most toxic to flax (IC50 = 9.83 $\times 10^{-6} / 9.25 \times 10^{-6}$ $\mathrm{mg} / \mathrm{ml}$ ), and least toxic to lupine (IC50 $=1.23 \times 10^{-3} / 1.16$ $\left.\times 10^{-3} \mathrm{mg} / \mathrm{ml}\right)$. The IC50 obtained while determining the 


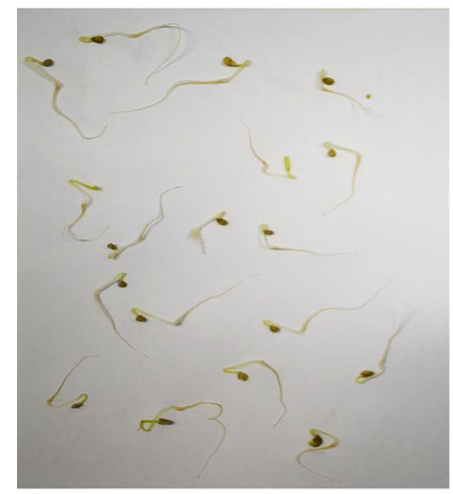

(A)

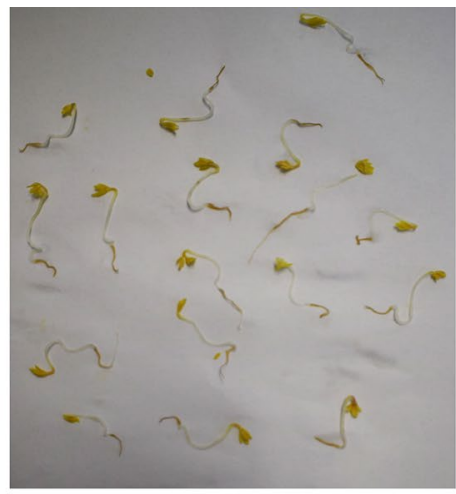

(B)

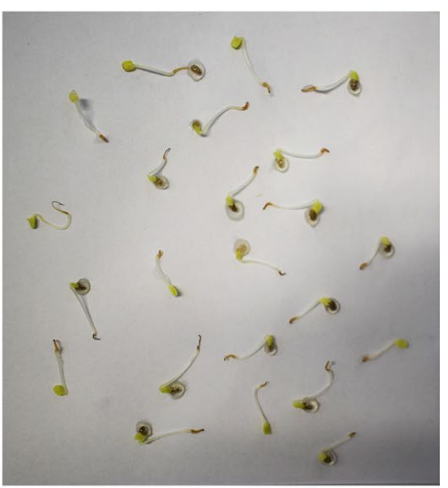

(C)

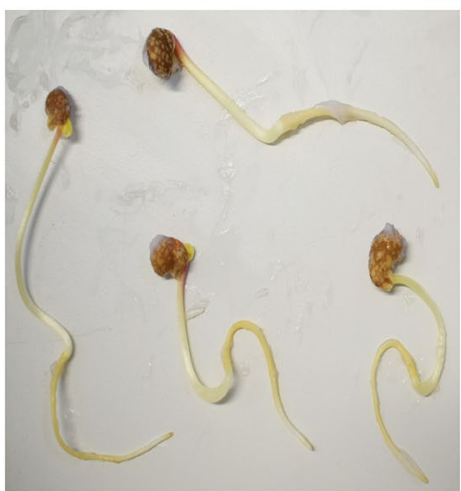

(D)

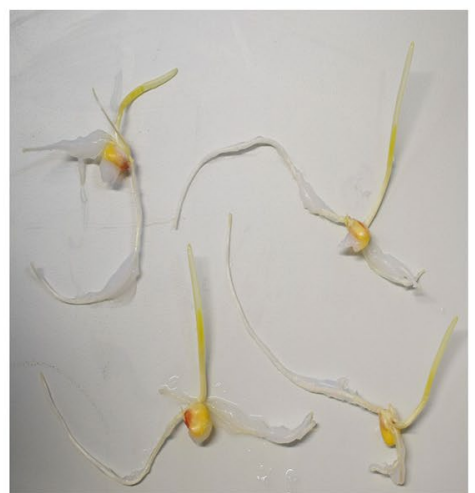

(E)

Fig. 5 Charts presenting the dependence of shoot growth activity on the concentration of $\mathrm{Ag} / \mathrm{Au}$ nanoparticles for: $\mathbf{a}$ tomato, $\mathbf{b}$ garden cress, $\mathbf{c}$ Chia, d lupine, e corn,

phytotoxicity of $\mathrm{Ag} / \mathrm{Au}$ nanoparticles was similar for corn, Salvia hispanica, tomato and garden cress. The equations, the square of correlation coefficient and the value of $\mathrm{IC}_{50}$ specified on the basis of experimental data are presented in Table 1.

G. urbanum $\mathrm{L}$ extracts diluted to $0.00875 \mathrm{mg} / \mathrm{ml}$ stimulated the growth of lupine, flax and garden cress; extracts diluted to $0.175 \mathrm{mg} / \mathrm{ml}$ stimulated the growth of Chia and tomatoes; and extracts diluted to $0.00875 \mathrm{mg} /$ $\mathrm{ml}$ stimulated the growth of corn. Then, as the concentration increased, the toxic effect was more severe. Dilutions of the $\mathrm{Ag} / \mathrm{Au}$ nanoparticle solution stimulated the growth of lupine at the concentration of $1.7 \times 10^{-7} / 1.6 \times 10^{-7}$ to $8.5 \times 10^{-5} / 8.0 \times 10^{-5} \mathrm{mg} / \mathrm{ml}$; of corn, flax and Chia-only at the concentration of $1.7 \times 10^{-7} / 1.6 \times 10^{-7} \mathrm{mg} / \mathrm{ml}$; of garden cress-at the concentration of $3.4 \times 10^{-7} / 3.2 \times 10^{-7} \mathrm{mg} / \mathrm{ml}$; and of tomato- at the concentration of $1.7 \times 10^{-6} / 1.6 \times 10^{-6}$ and $3.4 \times 10^{-6} / 3.2 \times 10^{-6} \mathrm{mg} / \mathrm{ml}$. This may be due to the increase in seed capsule permeability, which facilitates the passage of water and di-oxygen into cells, and accelerates metabolism and germination process [29]. Figure 5 presents the impact of certain concentrations of the $\mathrm{Ag} / \mathrm{Au}$ nanoparticle solution on the growth of selected plant shoots: (A) tomato $1 \% \mathrm{Ag} / \mathrm{Au}$; (B) garden cress $10 \% \mathrm{Ag} / \mathrm{Au}$; (C) Chia $1 \% \mathrm{Ag} / \mathrm{Au}$; (D) lupine 2.5\% Ag/Au; (E) corn $0.1 \% \mathrm{Ag} / \mathrm{Au}$.

Figures 6 and 7 present the charts of logarithmic dependence $A=a^{*} \ln (C)+b$ of the shoot growth activity on the concentration of $\mathrm{Ag} / \mathrm{Au}$ nanoparticles and G. urbanum $\mathrm{L}$ extract respectively for lupine, corn, flax, Chia, tomato and garden cress. The obtained study results confirm that metal nanoparticles can exhibit both positive and negative effect on higher plants [27]. One example of that are the studies demonstrating the impact of silver nanoparticles on crops like barley [30], wheat [31], Brassica [32] and radish [33], in which no significant negative impact of nanoparticles was found on any plant species. On the other hand, the studies carried out by Quah et al. [34] demonstrated that Ag nanoparticles with the diameter of $20-50 \mathrm{~nm}$ showed more substantial upward transport ability in crop species compared to bulk Ag (1-3 lm in diameter), and exhibited higher toxicity 
(A)

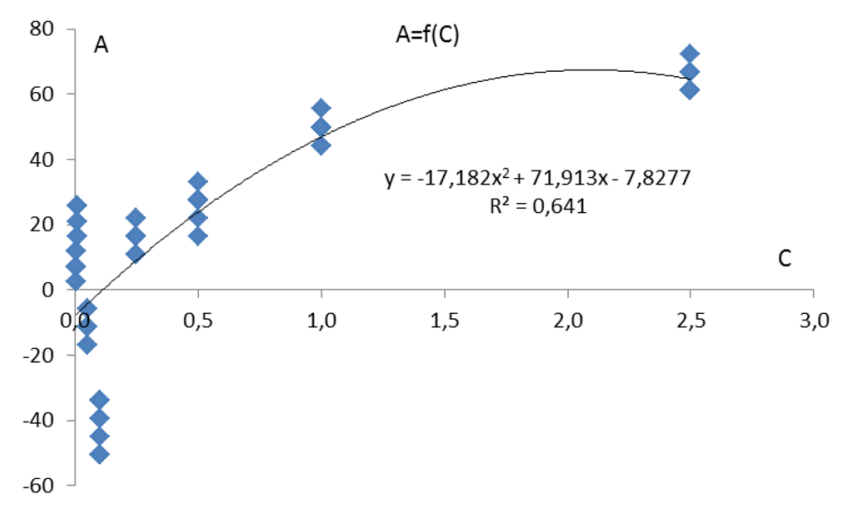

(C)

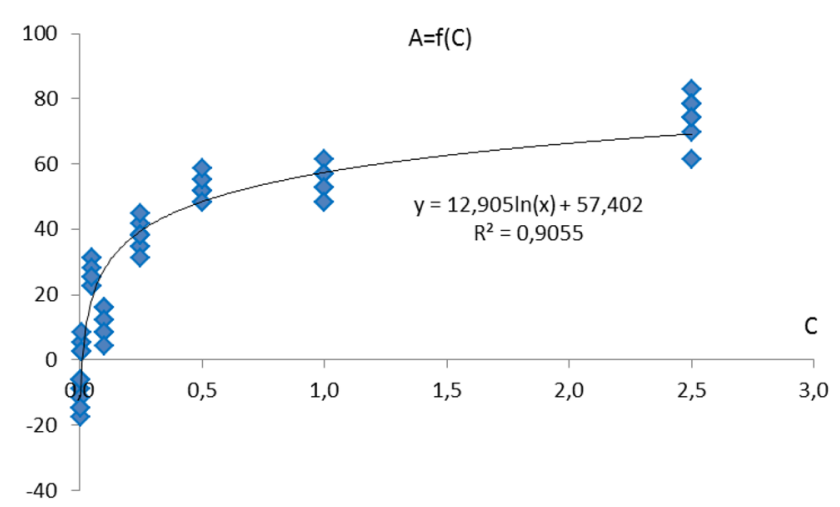

(E)

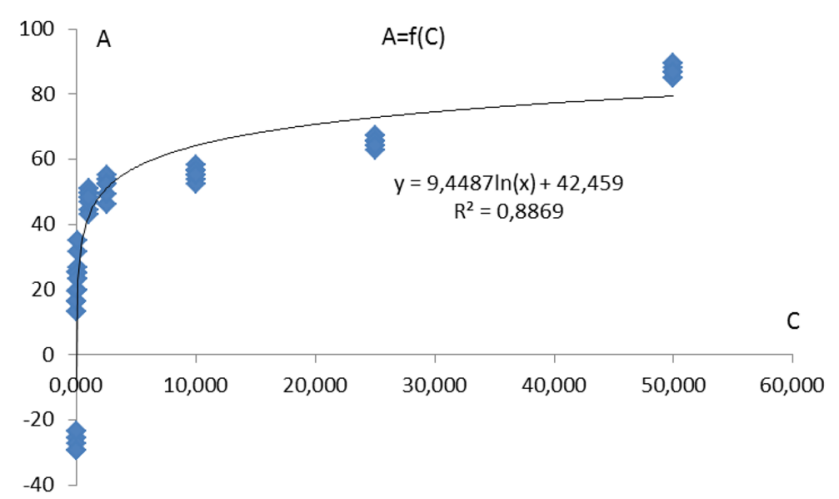

(B)

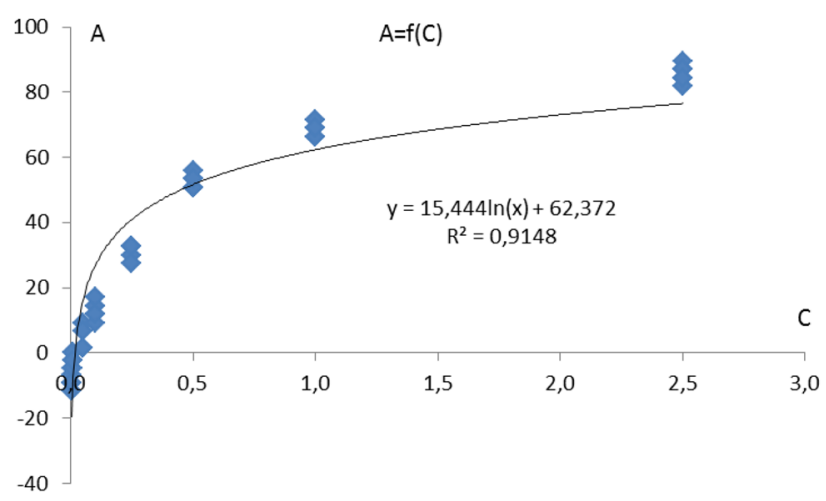

(D)

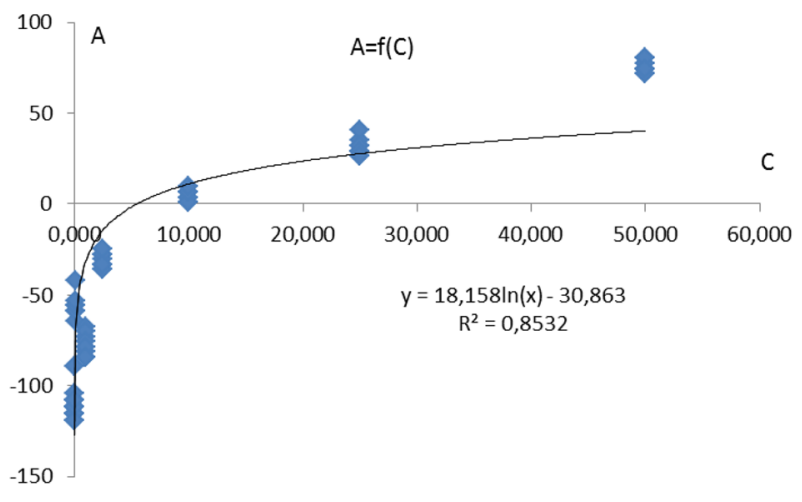

(F)

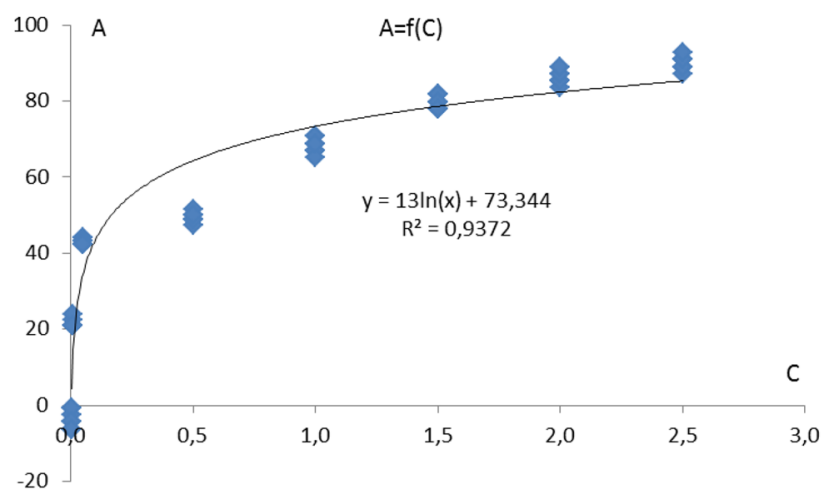

Fig. 6 The impact of different nanoparticle concentrations on the growth of: a tomato; $\mathbf{b}$ garden cress; $\mathbf{c}$ Chia; $\mathbf{d}$ lupine; e corn; $\mathbf{f}$ flax

to plants. Therefore, in addition to concentration, the size and shape of nanoparticles contribute to the toxic effect as well. As proven by the studies of Hao et al. [35] nanoparticles with a smaller diameter showed a more negative impact on rice biomass and phytohormone levels. Metal nanoparticles could be selectively absorbed, translocated and accumulated in specific plant tissues and cellular substructures, leading to various growing effects. 
(A)

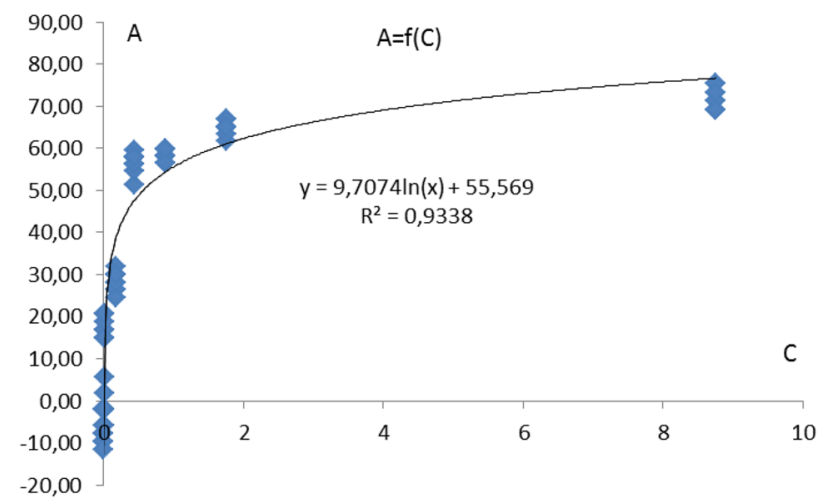

(C)

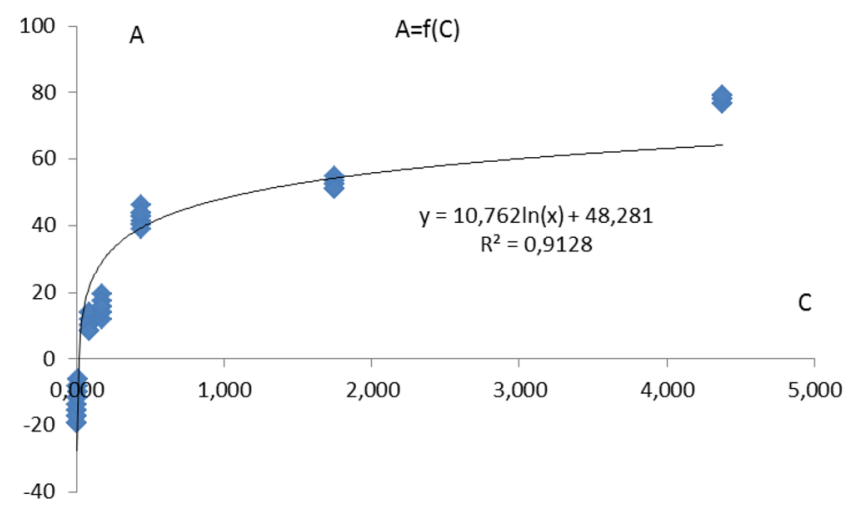

(E)

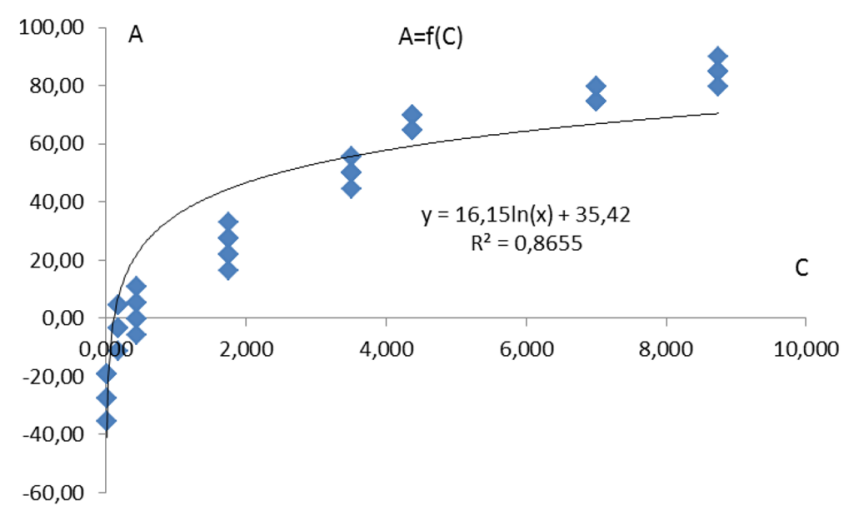

(B)

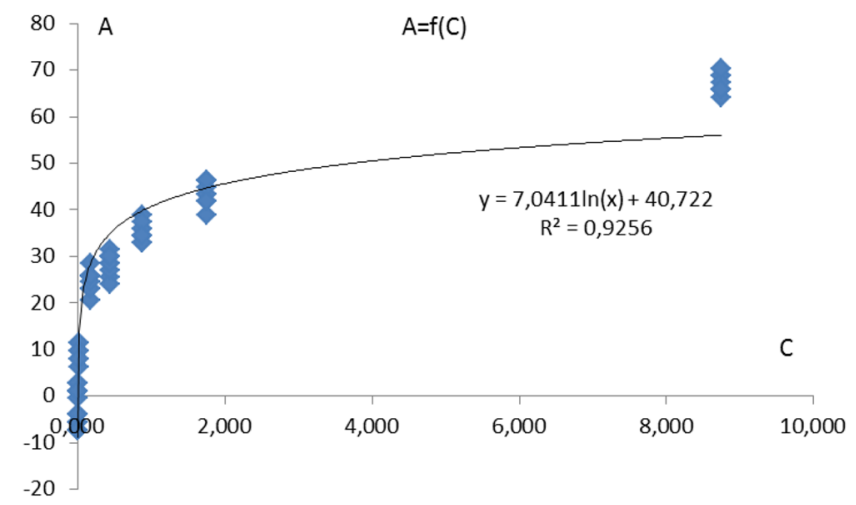

(D)

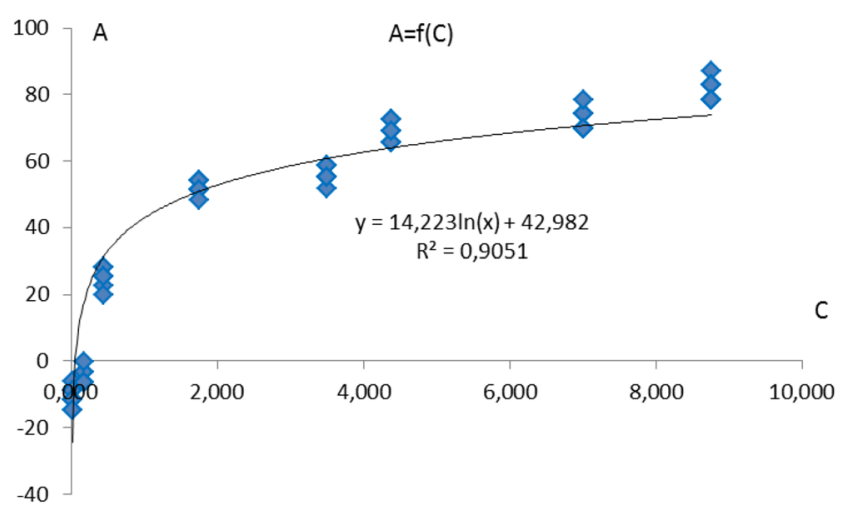

(F)

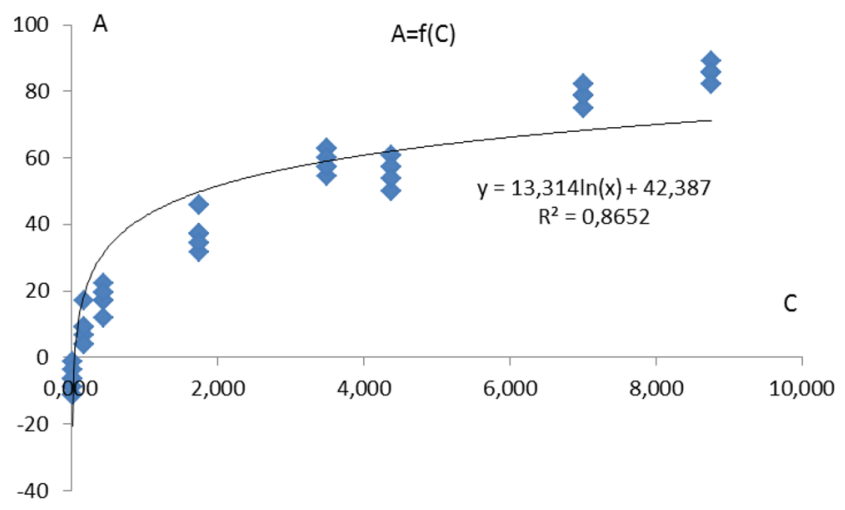

Fig. 7 Charts presenting the dependence of shoot growth activity on the concentration of G. urbanum extract for: a lupine, b corn, $\mathbf{c}$ flax, $\mathbf{d}$ Chia, e tomato, $\mathbf{f}$ garden cress

\section{Conclusion}

As the interest in nanotechnology is growing year by year, leading to the expansion of nanomaterial production, those compounds are becoming more widely spread in the environment. As a result, it is more possible that nanostructures will come into contact with living organisms and plants.
Such a situation may exacerbate the risk of adverse effects to the environment. As metal nanoparticles are widely applied in medicine, industry and the environment, this threat may exist also in this case. Therefore, exploration of the impact of metal nanoparticles on plants is an endeavor of vital significance. 
Therefore, this work was concerned with the assessment of the phytotoxicity of bimetallic $\mathrm{Ag} / \mathrm{Au}$ nanoparticles synthesized using $G$. urbanum L. extracts. The obtained bimetallic Ag/Au nanoparticles were characterized by UV-vis spectrophotometry (UV-vis), Transmission electron microscopy (TEM), Scanning electron microscopy (SEM), and Fourier transform infrared spectroscopy (FTIR). The microscopic studies made it possible to determine the size of the obtained nanoparticles, which was $50 \mathrm{~nm}$. As seeds and higher plants are used as model organisms in eco-toxicology in the short or long term, in this work, the phytotoxicity of biologically synthesized bimetallic nanoparticles and G. urbanum L. extract was assessed using the seeds of Lepidium sativum, Linum flavum, Zea mays, Solanum lycopersicum var. Cerasiforme and Salvia hispanica-Chia. The wide range of concentrations made it possible to observe the changes in selected plants caused by a stress factor. The solution of $\mathrm{Ag} / \mathrm{Au}$ nanoparticles was most toxic to flax (IC50 $=9.83 \times 10^{-6} / 9$. $25 \times 10^{-6} \mathrm{mg} / \mathrm{ml}$ ), and least toxic to lupine (IC50 $=1.23 \times 1$ $0^{-3} / 1.16 \times 10^{-3} \mathrm{mg} / \mathrm{ml}$ ). The IC50 obtained while determining the phytotoxicity of $\mathrm{Ag} / \mathrm{Au}$ nanoparticles was similar for corn, Salvia hispanica, tomato and garden cress. G. extract was most toxic to lupine (IC50 $=0.374 \mathrm{mg} / \mathrm{ml}$ ), and least toxic to corn $(\mathrm{IC} 50=4.635 \mathrm{mg} / \mathrm{ml})$.

Acknowledgements Research on synthesis financed from grant for young researchers in 2015 of the Ministry of Science and Higher Education.

\section{Compliance with Ethical Standards}

Conflict of interest The authors declare that they have no conflict of interest.

Open Access This article is licensed under a Creative Commons Attribution 4.0 International License, which permits use, sharing, adaptation, distribution and reproduction in any medium or format, as long as you give appropriate credit to the original author(s) and the source, provide a link to the Creative Commons licence, and indicate if changes were made. The images or other third party material in this article are included in the article's Creative Commons licence, unless indicated otherwise in a credit line to the material. If material is not included in the article's Creative Commons licence and your intended use is not permitted by statutory regulation or exceeds the permitted use, you will need to obtain permission directly from the copyright holder. To view a copy of this licence, visit http://creativecommons.org/licenses/by/4.0/.

\section{References}

1. C.M. Magdalane, K. Kaviyarasu, G.M.A. Priyadharsini, A.K.H. Bashir, N. Mayedwa, N. Matinise et al., Improved photocatalytic decomposition of aqueous Rhodamine-B by solar light illuminated hierarchical yttria nanosphere decorated ceria nanorods. J. Mater. Res. Technol. 8(3), 2898-2909 (2019)
2. K. Kaviyarasu, N. Geetha, K. Kanimozhi, C.M. Magdalane, S. Sivaranjani, A. Ayeshamariam et al., In vitro cytotoxicity effect and antibacterial performance of human lung epithelial cells A549 activity of zinc oxide doped $\mathrm{TiO} 2$ nanocrystals: investigation of bio-medical application by chemical method. Mater. Sci. Eng. C 74, 325-333 (2017)

3. K. Kaviyarasu, C.M. Magdalane, D. Jayakumar, Y. Samson, A.K.H. Bashir, M. Maaza et al., High performance of pyrochlore like Sm2Ti2O7 heterojunction photocatalyst for efficient degradation of rhodamine-B dye with waste water under visible light irradiation. J. King Saud Univ. Sci. 32(2), 1516-1522 (2020)

4. M. Filez, E.A. Redekop, J. Dendooven, R.K. Ramachandran, E. Solano, U. Olsbye et al., Formation and functioning of bimetallic nanocatalysts: the power of X-ray probes. Angew. Chem. Int. Ed. 58(38), 13220-13230 (2019)

5. M.I. Lerner, S.G. Psakhie, A.S. Lozhkomoev, A.F. Sharipova, A.V. Pervikov, I. Gotman, E.Y. Gutmanas, $\mathrm{Fe}-\mathrm{Cu}$ nanocomposites by high pressure consolidation of powders prepared by electric explosion of wires. Adv. Eng. Mater. 20(8), 1701024 (2018)

6. L. Li, H. Zheng, L. Guo, L. Qu, L. Yu, Construction of novel electrochemical sensors based on bimetallic nanoparticle functionalized graphene for determination of sunset yellow in soft drink. J. Electroanal. Chem. 833, 393-400 (2019)

7. R. Mandal, A. Baranwal, A. Srivastava, P. Chandra, Evolving trends in bio/chemical sensor fabrication incorporating bimetallic nanoparticles. Biosens. Bioelectron. 117, 546-561 (2018)

8. J.O. Adeyemi, E.E. Elemike, D.C. Onwudiwe, M. Singh, Bioinspired synthesis and cytotoxic evaluation of silver-gold bimetallic nanoparticles using Kei-Apple (Dovyalis caffra) fruits. Inorg. Chem. Commun. 109, 107569 (2019)

9. H.R. Rajabi, H. Deris, H.S. Faraji, A facile and green biosynthesis of silver nanostructures by aqueous extract of Suaeda acuminata after microwave assisted extraction. Nanochem. Res. 1(2), 177182 (2016)

10. H.R. Rajabi, R. Naghiha, M. Kheirizadeh, H. Sadatfaraji, A. Mirzaei, Z.M. Alvand, Microwave assisted extraction as an efficient approach for biosynthesis of zinc oxide nanoparticles: synthesis, characterization, and biological properties. Mater. Sci. Eng., C 78, 1109-1118 (2017)

11. Z.M. Alvand, H.R. Rajabi, A. Mirzaei, A. Masoumiasl, H. Sadatfaraji, Rapid and green synthesis of cadmium telluride quantum dots with low toxicity based on a plant-mediated approach after microwave and ultrasonic assisted extraction: synthesis, characterization, biological potentials and comparison study. Mater. Sci. Eng., C 98, 535-544 (2019)

12. Z.M. Alvand, H.R. Rajabi, A. Mirzaei, A. Masoumiasl, Ultrasonic and microwave assisted extraction as rapid and efficient techniques for plant mediated synthesis of quantum dots: Green synthesis, characterization of zinc telluride and comparison study of some biological activities. New J. Chem. 43(38), 15126-15138 (2019)

13. S. Sugimoto, K.I. Okuda, R. Miyakawa, M. Sato, K.I. AritaMorioka, A. Chiba et al., Imaging of bacterial multicellular behaviour in biofilms in liquid by atmospheric scanning electron microscopy. Sci. Rep. 6(1), 1-13 (2016)

14. P. Cvjetko, M. Zovko, P.P. Štefanić, R. Biba, M. Tkalec, A.M. Domijan et al., Phytotoxic effects of silver nanoparticles in tobacco plants. Environ. Sci. Pollut. Res. 25(6), 5590-5602 (2018)

15. D. Baderna, E. Lomazzi, A. Pogliaghi, G. Ciaccia, M. Lodi, E. Benfenati, Acute phytotoxicity of seven metals alone and in mixture: are Italian soil threshold concentrations suitable for plant protection? Environ. Res. 140, 102-111 (2015)

16. D.K. Tripathi, S. Singh, S. Singh, R. Pandey, V.P. Singh, N.C. Sharma et al., An overview on manufactured nanoparticles in plants: uptake, translocation, accumulation and phytotoxicity. Plant Physiol. Biochem. 110, 2-12 (2017) 
17. R. Chokkareddy, G.G. Redhi, Green synthesis of metal nanoparticles and its reaction mechanisms, in Green Metal Nanoparticles: Synthesis, Characterization and Their Application, eds. by S. Kanchi, S. Ahmed (2018), pp. 113-139

18. P. Malik, R. Shankar, V. Malik, N. Sharma, T.K. Mukherjee, Green chemistry based benign routes for nanoparticle synthesis. J. Nanopart. 2014, 1-14 (2014)

19. A.E. Al-Snafi, Constituents and pharmacology of Geum urbanuma review. IOSR J. Pharm. 9(5), 28-33 (2019)

20. Y. Huang, G.Y. Ding, P. Hu, Vitexnegheteroin M, a new phenolic glycoside from Vitex negundo var. heterophylla. Nat. Prod. Res. (2019). https://doi.org/10.1080/14786419.2019.1656628

21. A. Kuczerenko, K. Baczek, J.L. Przybyl, Z. Weglarz, Intraspecific variability of wild growing and cultivated common avens (Geum Urbanum 1.) In respect of accumulation of phenolic compounds. Pol. J. Agron. 18, 30-35 (2014)

22. M.E. Cuvelier, H. Richard, C. Berset, Antioxidative activity and phenolic composition of pilot-plant and commercial extracts of sage and rosemary. J. Am. Oil. Chem. Soc. 73(5), 645-652 (1996)

23. F. Shahidi, P.K. Janitha, P.D. Wanasundara, Phenolic antioxidants. Crit. Rev. Food Sci. Nutr. 32(1), 67-103 (1992)

24. S. Kumar, A.K. Pandey, Chemistry and biological activities of flavonoids: an overview. Sci. World J. 2013, 1-16 (2013)

25. J. Mayer, L.A. Giannuzzi, T. Kamino, J. Michael, TEM sample preparation and FIB-induced damage. MRS Bull. 32(5), 400-407 (2007)

26. P. Kaur, Biosynthesis of nanoparticles using eco-friendly factories and their role in plant pathogenicity: a review. Biotechnol. Res. Innov. 2(1), 63-73 (2018)

27. P. Debnath, A. Mondal, A. Hajra, C. Das, N.K. Mondal, Cytogenetic effects of silver and gold nanoparticles on Allium cepa roots. J. Genet. Eng. Biotechnol. 16(2), 519-526 (2018)
28. X. Zhang, X. Yuan, H. Shi, L. Wu, H. Qian, W. Xu, Exosomes in cancer: small particle, big player. J. Hematol. Oncol. 8(1), 83 (2015)

29. C.T. Hou, J.F. Shaw, Biocatalysis and Agricultural Biotechnology (CRC Press, Boca Raton, 2009).

30. N. Gruyer, M. Dorais, C. Bastien, N. Dassylva, G. Triffault-Bouchet, Interaction between silver nanoparticles and plant growth, in International Symposium on New Technologies for Environment Control, Energy-Saving and Crop Production in Greenhouse and Plant, vol. 1037 (2013), pp. 795-800

31. H.M. Jhanzab, A. Razzaq, G. Jilani, A. Rehman, A. Hafeez, F. Yasmeen, Silver nano-particles enhance the growth, yield and nutrient use efficiency of wheat. Int. J. Agron. Agric. Res. 7(1), 15-22 (2015)

32. M.C.M. Pallavi, R. Srivastava, S. Arora, A.K. Sharma, Impact assessment of silver nanoparticles on plant growth and soil bacterial diversity. 3 Biotech 6, 254 (2016)

33. N. Zuverza-Mena, R. Armendariz, J.R. Peralta-Videa, J.L. GardeaTorresdey, Effects of silver nanoparticles on radish sprouts: root growth reduction and modifications in the nutritional value. Front. Plant Sci. 7, 90 (2016)

34. B. Quah, C. Musante, J.C. White, X. Ma, Phytotoxicity, uptake, and accumulation of silver with different particle sizes and chemical forms. J. Nanopart. Res. 17(6), 277 (2015)

35. Y. Hao, B. Xu, C. Ma, J. Shang, W. Gu, W. Li et al., Synthesis of novel mesoporous carbon nanoparticles and their phytotoxicity to rice (Oryza sativa L). J. Saudi Chem. Soc. 23(1), 75-82 (2019)

Publisher's Note Springer Nature remains neutral with regard to jurisdictional claims in published maps and institutional affiliations. 